\title{
ANALISIS DAN DESAIN SISTEM INFORMASI PROGRAM RUJUK BALIK (PRB) OBAT DI BPJS KOTA TANGERANG
}

\author{
ROHMAT TAUFIQ ${ }^{1)}$, FITRIA NURAINI'), \& YANUARDI ${ }^{3)}$ \\ Program Studi Teknik Informatika \\ Fakultas Teknik Universitas Muhammadiyah Tangerang \\ Jl. Perintis Kemerdekaan I/33 Cikokol Kota Tangerang - Banten \\ Email: rohmat.taufiq@umt.ac.id, fitrianuraini745@gmail.com, \\ yanuardi99@gmail.com
}

\begin{abstract}
ABSTRAK
BPJS Kesehatan merupakan penyelenggara program jaminan sosial di bidang kesehatan. BPJS Kesehatan telah menerapkan aplikasi apotek online, pada era JKN apotek dapat berperan sebagai apotek Program Rujuk Balik (PRB) atau apotek jejaring dan apotek klinik pertama. Aplikasi apotek online adalah salah satu program unggulan guna meningkatkan kualitas pelayanan serta memudahkan akses pelayanan kesehatan kepada pasien yang memakai JKN-KIS. Pelayanan Obat Rujuk Balik adalah pemberian obat-obatan untuk penyakit kronis di Faskes Tingkat Pertama sebagai bagian dari program pelayanan rujuk balik. Proses penagihan biaya obat di apotek online yaitu obat apotek program rujuk balik diklaim langsung ke BPJS Kesehatan. Dalam menganalisa sistem yang berjalan digunakan metode analisa dan penggambaran sistem menggunakan Unified Modelling Language (UML) dan dalam pengumpulan data digunakan metode wawancara dan observasi. Hasil dari penelitian ini adalah sebuah hasil analisis berupa masukan-masukan tentang aplikasi sistem informasi yang nantinya bisa digunakan untuk memudahkan proses pengembangan sistem informasi berbasis web yang sudah ada.
\end{abstract}

Kata Kunci: BPJS Kesehatan, Apotek Online, Program Rujuk Balik, UML.

\section{PENDAHULUAN}

Dalam era globalisasi dunia seperti sekarang ini, perkembangan kegiatan-kegiatan pekerjaan di beberapa perusahaan sudah mengalami kemajuan yang sangat pesat dibandingkan dengan era sebelumnya. Hal ini ditandai dengan semakin berkembangnya pemakaian komputer dalam pengolahan data-data yang selalu terupdate dan user friendly. Hampir semua perusahaan berupaya untuk melakukan perubahan untuk melakukan system kerja yang sudah ada karna sistem yang diterapkan hampir tidak layak digunakan untuk kegiatan operasional peruahaan terutama didalam melakukan pengolahan data yang rumit dan bersifat rutinitas.

BPJS Kesehatan (Badan Penyelenggara Jaminan Sosial Kesehatan) merupakan badan usaha milik negara yang ditugaskan khusus oleh pemerintah untuk menyelenggarakan jaminan pemeliharaan kesehatan bagi seluruh rakyat Indonesia, terutama untuk Pegawai Negri Sipil, Penerima Pensiun PNS dan TNI/POLRI, Veteran, Perintis Kemerdekaan beserta keluarganya dan Badan Usaha lainnya ataupun rakyat biasa.

BPJS Kesehatan merupakan penyelenggara program jaminan sosial di bidang kesehatan yang merupakan salah satu dari lima program dalam Sistem Jaminan Sosial Nasional (SJSN), yaitu Jaminan Kesehatan, Jaminan Kecelakaan Kerja, Jaminan Hari Tua, Jaminan Pensiun, dan Jaminan Kematian sebagaimana tercantum dalam Undang-Undang Nomor 40 Tahun 2004 tentang Sistem Jaminan Sosial Nasional.

BPJS Kesehatan telah menerapkan aplikasi apotek online, dalam implementasinya BPJS kesehatan terus berupaya meningkatkan kepuasan peserta. Inovasi-inovasi terus dilakukan untuk dapat mempermudah peserta dan fasilitas kesehatan (Faskes) kerja sama dalam 
mendapatkan pelayanan. Inovasi terkait dengan Teknologi Informasi (TI) terus dikembangkan guna memudahkan faskes dalam hal ini apotek untuk mempermudah layanan klaim obat di luar paket agar proses klaim lebih mudah dan cepat. BPJS Kesehatan Cabang Cikokol melakukan sosialiasi mengani Apotek Online tersebut kepada apotek mitra BPJS Kesehatan guna memberikan pemahaman dan tata cara penggunaan aplikasi apotek tersebut. Dengan adanya aplikasi apotek online, faskes dapat mempercepat proses penagihan klaim obat luar paket, dapat menggambarkan riwayat pelayanan obat setiap peserta JKN-KIS secara realtime online, dan dapat melaporkan keluhan ketersediaan obat secara online. Pengentrian resep pada aplikasi apotek online yang memerlukan data kunjungan $P$-Care Online dari FKTP dan data SEP online dari rumah sakit sehingga semua tersistem secara online. Dengan ini diharapkan bisa mempermudah apotek dalam melayani peserta JKN-KIS.

Aplikasi apotek online ini di kembangkan untuk mempermudah apotek kerja sama dengan BPJS Kesehatan untuk melakukan entri dan penagihan klaim obat di luar paket. Sehingga prosesnya akan menjadi mudah dan cepat serta diharapkan dengan dikembangkannya sistem ini tentunya kepuasan peserta dan Faskes terhadap BPJS Kesehatan bisa semakin meningkat.

Menurut hasil Analisa kami ada beberapa point yang masih bisa dikembangkan yaitu prosedur akses aplikasi apotik online yang terlalu Panjang, keluhan yang terjadi pada aplikasi apotek online dalam hal memverifikasi obat dan yang ketiga adanya penumpukan berkas-berkas dari pihak apotek ke BPJS Kesehatan.

\section{TINJAUAN PUSTAKA \\ 1. Analisis}

Menurut Spradley dalam Sugiyono (2012) mengatakan bahwa "Analisis adalah sebuah kegiatan untuk mencari suatu pola selain itu analisis merupakan cara berpikir yang berkaitan dengan pengujian secara sistematis terhadap sesuatu untuk menentukan bagian, hubungan antar bagian dan hubungannya dengan keseluruhan."

\section{Sistem Informasi}

Sedangkan menurut Maniah (2017), sistem dapat didefinisikan sebagai elemen-ele- men berupa data, jaringan kerja dari prosedurprosedur yang saling berhubungan, sumber daya manusia, teknologi baik hardware maupun software yang saling berinteraksi sebagai satu kesatuan untuk mencapai tujuan/sasaran tertentu yang sama.

Menurut Taufiq (2013) sistem adalah kumpulan dari sub-sub sistem baik abstrak maupun fisik yang saling terintegrasi dan berkolaborasi untuk mencapai suatu tujuan tertentu sedangakn informasi adalah data-data yang diolah sehingga memiliki nilai tambah dan bermanfaat bagi pengguna.

Ciri-ciri informasi yang berkualitas menurut Romney dan Steinbart (2006) dalam Taufiq (2018) adalah Relevant, Reliable, Complete, Timely, Understanable, Variable dan Accessible.

\section{Program Rujuk Balik}

Pelayanan Obat Rujuk Balik adalah pemberian obat-obatan untuk penyakit kronis di Faskes Tingkat Pertama sebagai bagian dari program pelayanan rujuk balik.

Pelayanan Rujuk balik adalah Pelayanan kesehatan yang diberikan kepada penderita di Fasilitas Kesehatan atas rekomendasi/rujukan dari Dokter Spesialis/Sub Spesialis yang merawat. Pelayanan Program Rujuk Balik adalah pelayanan kesehatan yang diberikan kepada penderita penyakit kronis dengan kondisi stabil dan masih memerlukan pengobatan atau asuhan keperawatan jangka panjang yang dilaksanakan di Faskes Tingkat Pertama atas rekomendasi/rujukan dari Dokter Spesialis/ Sub Spesialis yang merawat. Idris (2014).

\section{Obat}

Menurut SK Menteri Kesehatan No.25/ Kab/B.VII/ 71 tanggal 9 Juni 1971, yang disebut dengan obat ialah suatu bahan atau paduan bahan-bahan untuk digunakan dalam menetapkan diagnosis, mencegah, mengurangi, menghilangkan, menyembuhkan penyakit, luka atau kelainan badaniah dan rohaniah pada manusia atau hewan, memperelok badan atau bagian badan manusia. Menurut Ansel (2005), obat adalah zat yang digunakan untuk diagnosis, mengurangi rasa sakit, serta mengobati atau mencegah penyakit pada manusia atau hewan. Obat dalam arti luas ialah setiap zat kimia yang dapat mempengaruhi proses hidup, maka farmakologi merupakan ilmu yang sangat luas cakupannya. 


\section{BPJS Kesehatan}

Pasal 1 ayat 1 UU tentang Jaminan social menjelaskan bahwa Jaminan sosial adalah salah satu bentuk perlindungan sosial untuk menjamin seluruh rakyat agar dapat meneuhi kebutuhan dasar hidupnya yang layak (UU No. 40 Tahun 2004). Penyelenggaraan Jami-nan Kesehatan Nasional mengacu pada prin-sipprinsip Sistem Jaminan Sosial Nasional (SJSN) seperti yang dijelaskan dalam Undang-undang nomor 40 Tahun 2004 tentang SJSN adalah sebagai berikut: prinsip kegotong-royongan, nirlaba, keterbukaan, kehatihatian, akuntabiltias, portabiltias, kepersetaan wajib, dana amanat dan prinsip hasil pengelolaan dana jaminan sosial.

\section{METODE PENELITIAN}

Langkah yang dilakukan dalam penelitian ini adalah sebagai berikut:

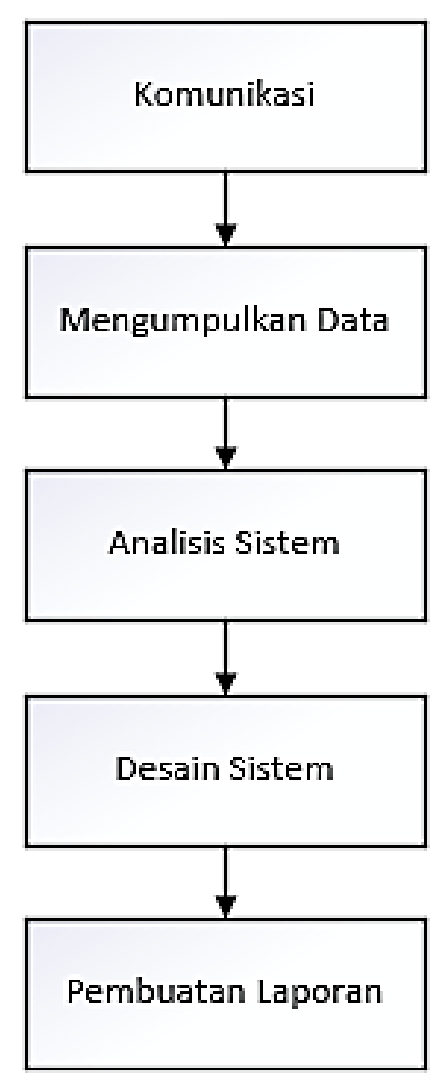

Gambar 1. Metode Penelitian.

\section{ANALISIS DAN DESAIN}

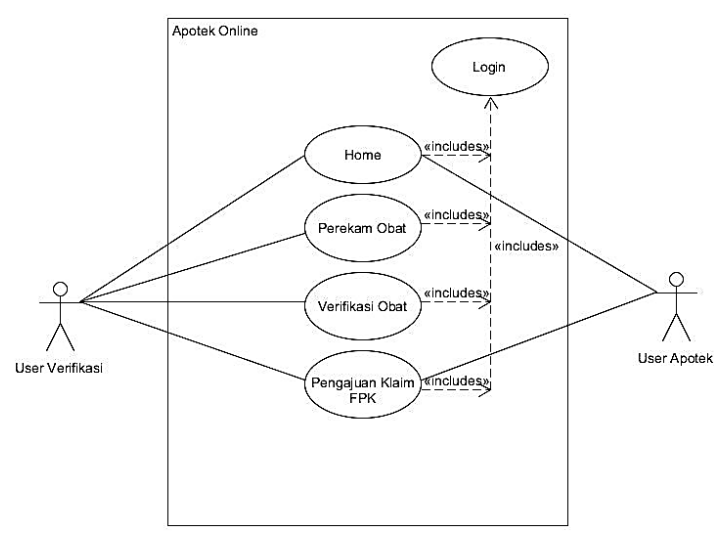

Gambar 2. Use case Diagram.

Dari gambar tersebut dijelaskan bahwa actor adalah user varifikator dan user apotek dan case diantaranya Home, Perekam obat, Verifikasi Obat, Pengajuan Klaim FPK dan Referensi sebagai berikut:

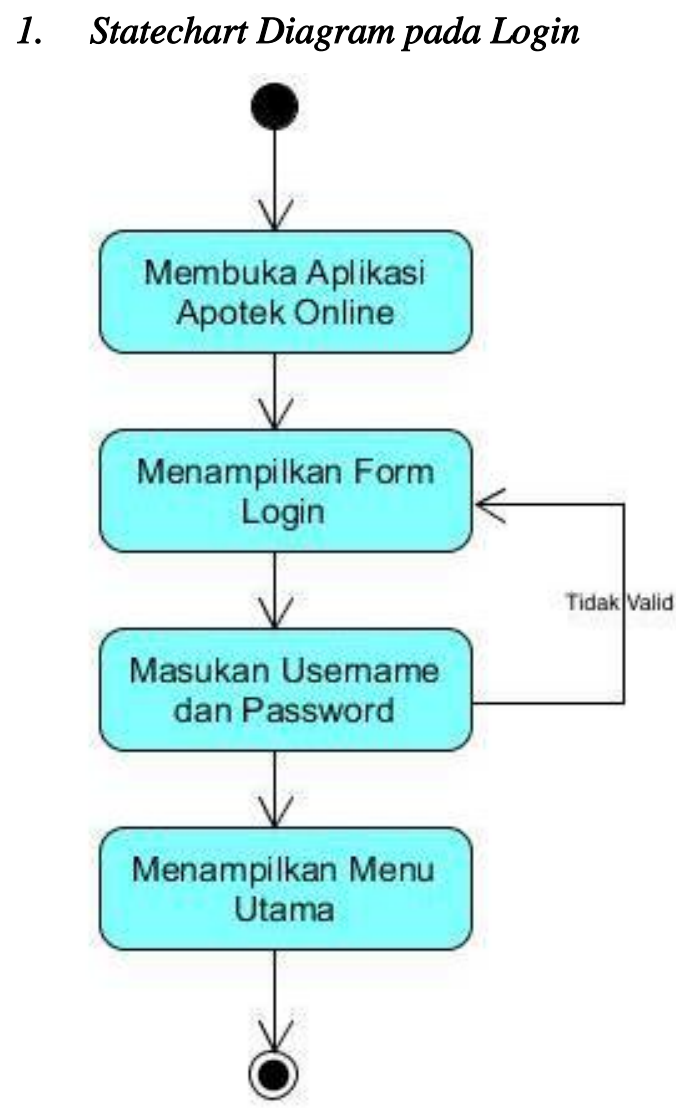

Gambar 3. Statechart Diagram Login. 


\section{Statechart Diagram Rekam Obat}

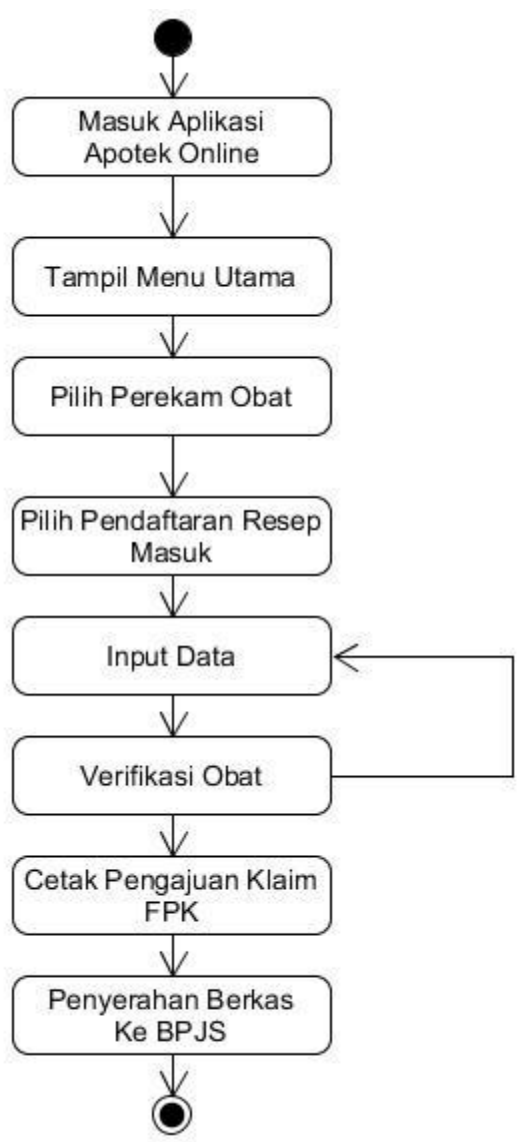

Gambar 4. Statechart Diagram Rekam Obat.

\section{Analisis Statechart Diagram Pada Peng- ajuan Klaim Obat}

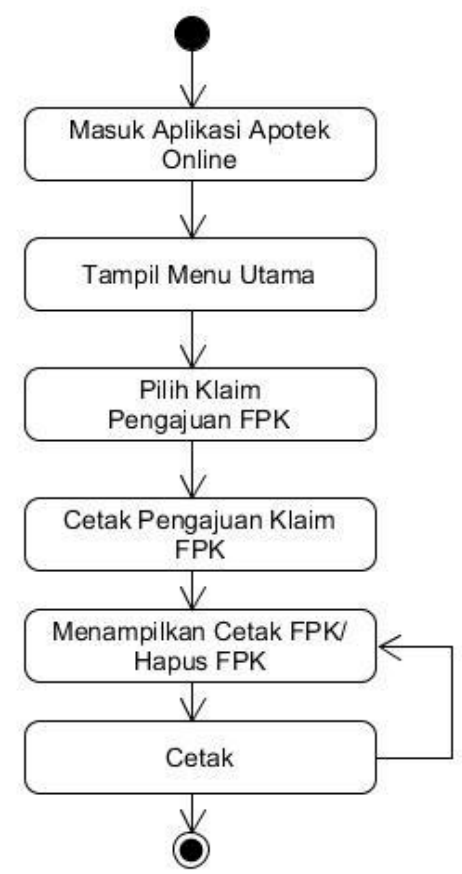

4. Activity Diagram Login

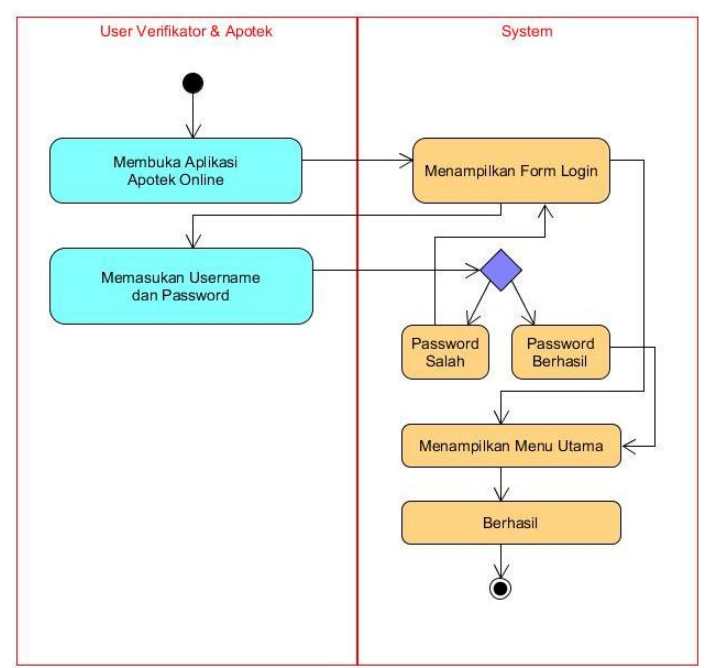

Gambar 6. Actifity Diagram Login.

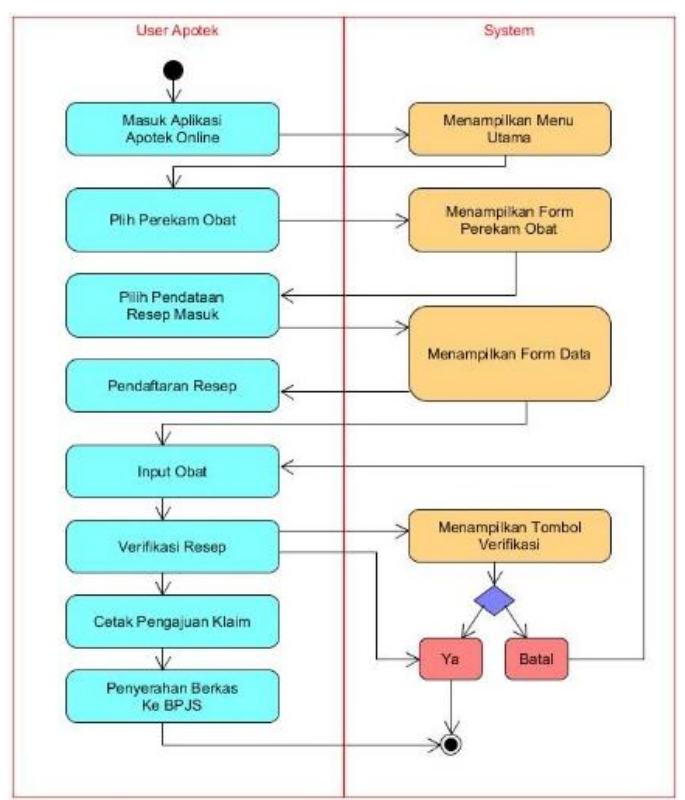

Gambar 7. Actifity Diagram Perekam Obat

Gambar 5. Statechart Diagram Pengajuan Klaim. 


\section{Activity Diagram Pengajuan Klaim}

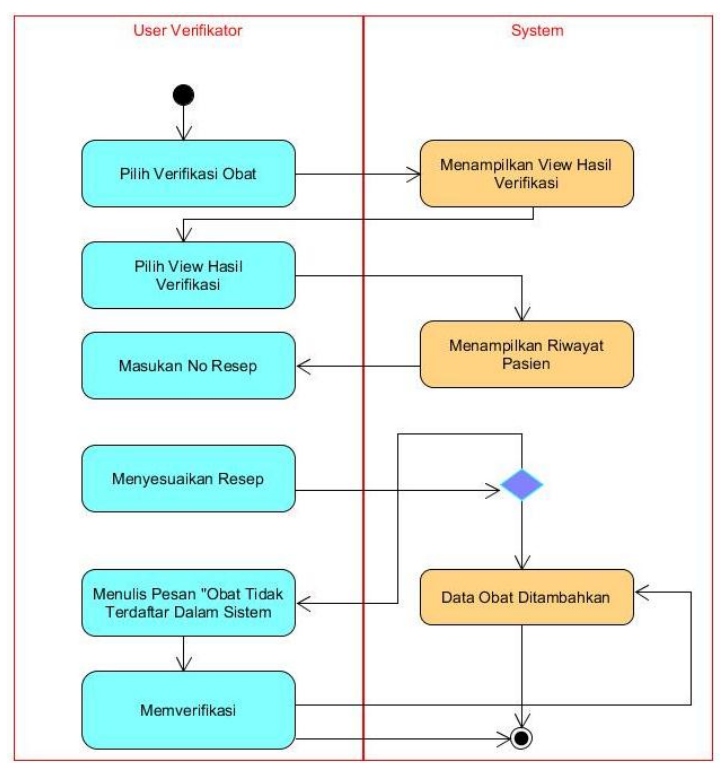

Gambar 8. Activity Diagram Verifikasi Obat.

\section{Analisis Pada Sequence Diagram Login}

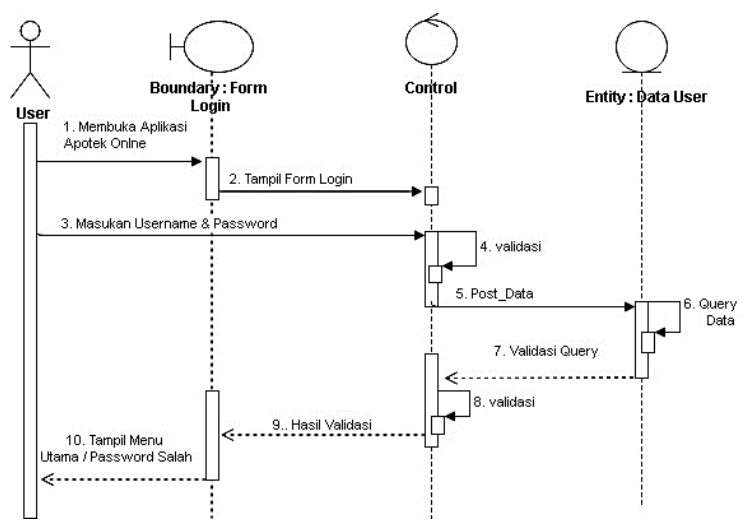

Gambar 9. Sequence Diagram Login

\section{Analisis pada sequence diagram Perekam Obat}

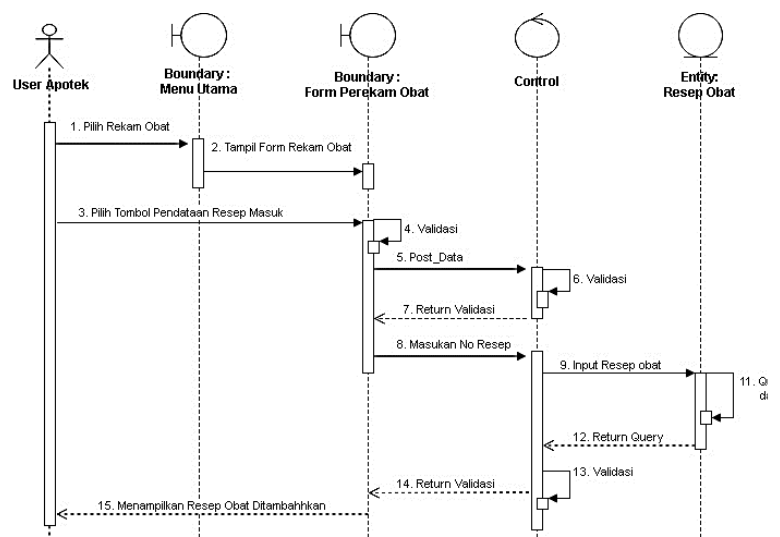

Gambar 10. Sequence Diagram Rekam Obat.

\section{Analisis Pada Sequence Diagram Peng- ajuan Klaim Obat}

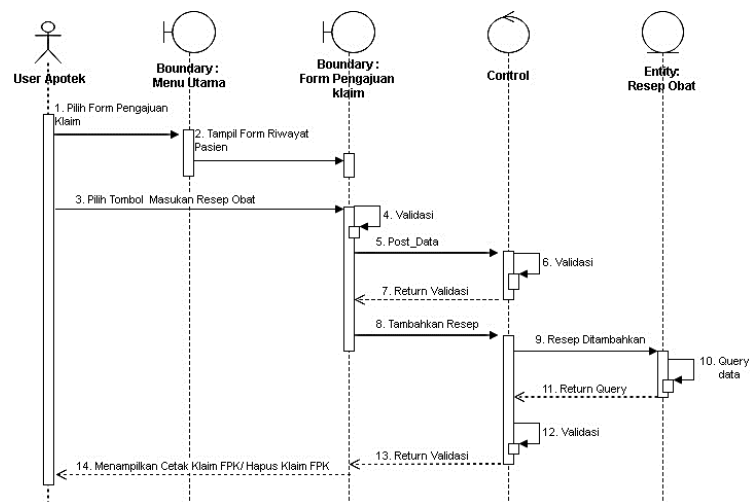

Gambar 11. Sequence Diagram Pengajuan Klaim Obat.

\section{Desain Tampilan}

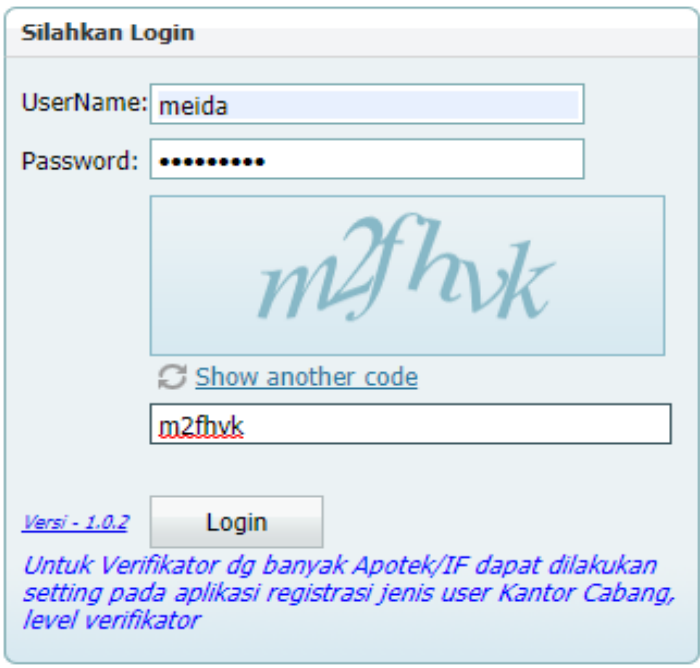

Gambar 12. Tampilan Login Aplikasi Apotek Online.

\section{Tampilan Perekam Obat}

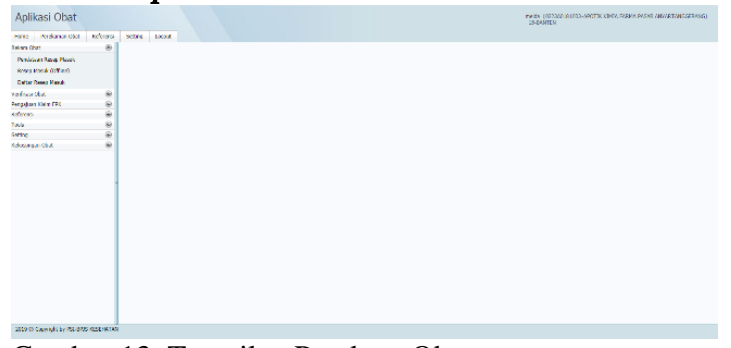

Gambar 13. Tampilan Perekam Obat.

\section{Tampilan View Verifikasi Obat}

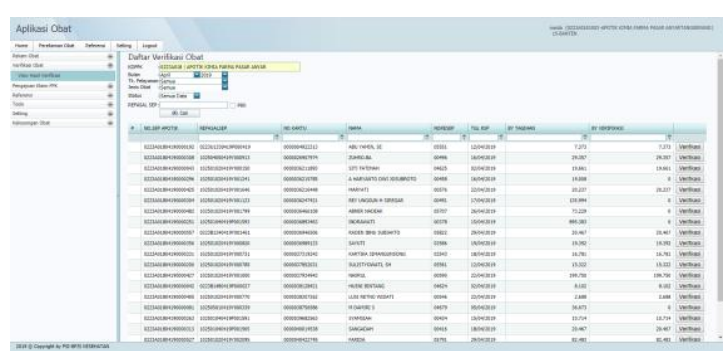

Gambar 14. View Verifikasi Obat. 


\section{Tampilan Verifikasi Obat}

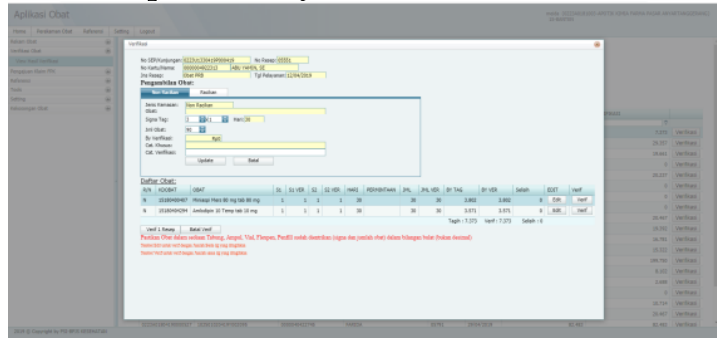

Gambar 15. Verifikasi Obat.

\section{KESIMPULAN}

Untuk meningkatkan kepuasan peserta, disarankan BPJS Kesehatan dapat mempertahankan dan meningkatkan kualitas pelayanannya yang diwujudkan dengan lima dimensi kualitas jasa, yaitu tangible, reability, responsiveness, assurance serta empathy. Diantaranya ialah menyediakan fasilitas-fasilitas yang lebih baik lagi untuk kenyamanan peserta serta lebih meningkatkan lagi pelayanan yang diberikan oleh petugas yang bertugas dalam menangani keluhan yang disampaikan peserta BPJS Kesehatan. Sehingga dengan dipertahankan dan ditingkatkannya pelayanan yang diberikan akan meningkat pula kepuasan peserta terhadap BPJS Kesehatan.

\section{DAFTAR PUSTAKA}

Ansel, H. C., 2005, Pengantar Bentuk Sediaan Farmasi, diterjemahkan oleh Ibrahim, F., Edisi IV, 605-619, Jakarta, UI Press.

Fachmi Idris (2014). Panduan Praktis Program Rujuk Balik Bagi Peserta JKN.

Maniah (2017:1). Analisis dan Perancangan Sistem Informasi. Yogyakarta: Deepublish.

R. Taufiq (2013). Sistem Informasi Manajemen: Konsep Dasar, Analisis dan Metode Pengembangan. Yogyakarta: Graha Ilmu.

R. Taufiq (2018). Pengantar Sistem Informasi. Jakarta: Mitra Wacana Media.

Sugiyono (2012). Metodelogi Penelitian Kombinasi (Mixed Methods). Bandung: Alfabeta.

Surat Keputusan Menteri Kesehatan Republik Indonesia No.:193/Kab/B.VII/71.

Undang-Undang Republik Indonesia Nomor 40 Tahun 2004 Tentang Sistem Jaminan Sosial Nasional. 